\title{
Food quality and the heterogeneous spatial distribution of meiofauna
}

\author{
J. J. Lee 1 , J. H. Tietjen', C. Mastropaolo $\&$ H. Rubin ${ }^{2}$ \\ 1 Department of Biology, \\ City College of City University of New York; New York, \\ and \\ 2 Department of Mathematics, \\ Hunter College of City University of New York; New York, USA
}

\begin{abstract}
Several different experimental approaches were used to examine recruitment of benthic meiofauna to patches of selected species of algae. In one approach algal-coated, baited slides were incubated in a salt marsh littoral benthos. The second approach employed patches of algae arrayed equidistantly around an inoculum of meiofauna in a petri dish. Meiofauna were shown to be selectively recruited to patches of some species of algae but not to others. The evidence obtained supports a hypothesis that selective recruitment of meiofauna can be one mechanism which establishes the spatial heterogeneity so often observed in natural collections of meiofauna.
\end{abstract}

\section{INTRODUCTION}

Spatial and temporal heterogeneity of abiotic resources and organisms, at various hierarchies of scale, are commonplace in the natural world. We must presume that interacting species and the communities in which they co-evolved function effectively in this environmental mosaic or else they would not persist today. Quite some time has passed since Hutchinson \& MacArthur (1959) concluded that there was a continuous functional relationship between the size of the animal and the size of the mosaic elements of their environment. Though it would seem that the high species diversity of protozoa and small metazoa, their generally high reproductive rates and the mosaic nature of the environment at scales meaningful to them would have attracted many ecologists to use them to study mechanisms of community organization or structure, the specialized skills required for observation and manipulation and the proportionally greater time required in the identification of small organisms have not encouraged too many.

At present it seems easier to develop conceptual frameworks for understanding the mosaic structural and functional relationships in communities dominated by large sessile organisms (e.g. Pielou, 1975) than it does for communities with less, or relatively short lived, structural permanence (e.g. Steele, 1973). In those communities which 
have been studied most intensively competition and predation seem to be the mechanisms which organize community structure (e.g. Connell, 1975). Through there is less documentation on this point, asexual reproduction and functionally similar phenomena (i.e. iteropary) seem to provide an additional major mechanism which operates in weaving communities from diverse assemblages of large numbers of small organisms with high reproductive rates.

Current ecological thinking suggests that resource partitioning by food type is more important for animals feeding on food that is large in relation to their own size than it is for animals feeding on relatively small food items (Schoener, 1974). Experimental evidence for protozoa (e.g. Fenchel, 1968; Lee, 1974; Rubin \& Lee, 1976) and meiofauna (e.g. Provasoli et al., 1959; Tietjen et al., 1970; Lee et al., 1076) indicates that this concept is particularly applicable to the smallest animals. A conceptual framework for micro and meiofaunal resource optimization within an environmental mosaic could be based on successive responses of the animals to asexual blooms of different species of microflora. Species of littoral foraminifera, for instance, are known to feed, grow and reproduce quite rapidly in response to particular algal blooms (Lee et al., 1966; Lee \& Muller, 1973). The explosive bursts of reproduction could lead to the extremely heterogeneous distribution of these animals which have been found in nature (Buzas, 1965, 1969; Lee et al., 1969; Matera \& Lee, 1972).

Is it equally plausible that heterogeneity could develop in the small animal community as a consequence of selective recruitment of these animals to specific blooms of algae? At the onset of our experiments, we were unaware of any specific experiments which demonstrated that selective recruitment to algal patches could be a mechanism for structuring communities populated by very small animals.

\section{MATERIALS AND METHODS}

Two distinctly separate approaches were used in these experiments. In one approach algal slides were used as bait to attract meiofauna in the environment. The algae used were all isolated in axenic culture from littoral benthic habitats in North Eastern U.S. salt marshes. Algae were chosen for the experiment principally because they have been shown in previous experiments to be good food organisms for one or more species of salt marsh meiofauna (Lee et al., 1966, 1970, 1971; Muller \& Lee, 1969; Tietjen \& Lee, 1973, 1977; Muller, 1975). The algae used in both experimental approaches were: Cylindrotbeca closterium (strain 9), Amphora acutiuscula var. coffeaeformis (B1 17), Acbnantbes hauckiana (110), Nitzschia acicularis (8), Nitzschia sp. (123), Phaeodactylum tricornutum (39), Dunaliella salina (13), Chlamydomonas subcordiformis (94), Chlorococcum sp. (38), Nanochloris sp. (41), and Fragilaria sp. (B1 $714 \mathrm{~B})$. Sterilized microscope slides were aseptically dipped in sterile molten sea water agar $(1.5 \%$ agar $[\mathrm{w} / \mathrm{v}]$ in local sea water) and then placed in sterile Coplin jars. When the agar hardened, a logarithmically growing algal culture was aseptically transferred to the Coplin jars. After 7 days incubation in the light $\left(25^{\circ} \mathrm{C} ; 18 \mathrm{~h} \mathrm{light} /\right.$ $6 \mathrm{~h}$ dark) the slides were transferred to commercial microscope slide holders (made for staining 5 slides at a time) which gripped the slides at one end. The slides and slide 
holders in turn were inserted into a set of in situ incubators which we fabricated from lucite cylinders and flat sheets of the same plastic. The incubators were designed to hold 4 slide holders (Peel-a-Way Sci Div., W. Glen Wunderly Co., South el Monte, California) (with each 3 slides) in immediate contact with the benthic substratum. The walls of the incubators were perforated with small holes $(0.5 \mathrm{~cm})$ to permit free exchange of sea water without exposing the slides to macrofauna, and the bottom of the incubators were surrounded with a wide flange which prevented them from sinking into the substratum. There were 4 incubators to a set which were tied by means of nylon ropes to each other and staked so that each incubator was in a quadrant of $\mathrm{m}^{2}$. In order to study both recruitment and reproduction, incubation times were varied from 2 days to several weeks. Control slides (sea water-agar controls) were randomized with experimental slides and were present in all subsets. At harvest the slide holders were gently removed from the incubators and individual slides were inserted into plastic cytological slide mailing tubes filled with a sodium bicarbonate buffered Rose Bengal-formalin mixture. The organisms on the surface of the slides and in the mailing tubes were examined under a dissecting microscope and when necessary under a compound microscope. The organisms were enumerated only to major group.

The second approach ("cafeteria") to the problem was basically a laboratory one. Large petri dishes $(150 \mathrm{~mm} \times 15 \mathrm{~mm})$ were the experimental vessels. They were very carefully filled on a perfectly level surface with $40 \mathrm{ml}$ of sea water agar. Stock cultures of the same experimental algae were grown on similarly prepared plates except that the medium was richer ("S" agar; Lee et al., 1970). An alcohol sterilized \# 10 cork borer was used to remove a central and 8 equidistant peripheral plugs of agar from the experimental plates. A template placed under the plates aided the processes. Number 10 plugs of algae from the stock plates were aseptically placed in four alternate peripheral holes in the experimental plates. The alternate spaces between algal patches were filled with plugs of " $S$ " medium agar. Control plates were filled with plugs of "S" agar in all 8 positions. Two series of experiments were conducted in the petri dishes. In the first series synxenic cultures of individual meiofaunal species. Chromadorina germanica (nematode), Nitocra typica (harpacticoid copepod), Leptocaris brevicornis (harpacticoid copepod), Allogromia laticollaris (foraminifera) and Rhabditis marina (nematode) were inoculated into the central well. In the second series of experiments, $1 \mathrm{ml}$ of freshly collected meiofauna (sieved through $500 \mu \mathrm{m}$ mesh) from littoral aufwuch communities in the greater Sippewissett salt marsh (Falmouth, Mass., USA) was used as inoculum. After the experimental animals were introduced into the central wells, $20 \mathrm{ml}$ of sterile sea water was very carefully pipetted onto the surface of the petri plates to make a thin aqueous film above the plates. (The special care was necessary to prevent dislodging and distribution of the meiofauna from the central well during the flooding of the plates.) The plates were incubated on a laboratory bench which had a bank of fluorescent lamps $\sim 30 \mathrm{~cm}$ above it. The lights were cycled every $12 \mathrm{~h}$. The experiments were harvested at either 4 or 10 days. A \# 15 cork borer was used to remove an area slightly larger than the original algal or control patches. The plugs were harvested into small vials containing a buffered Rose Bengal-formalin solution. During incubation and harvest great care was exercised not to agitate the experimental vessels. Each experiment was replicated twice. 
Food quality and spatial distribution of meiofauna

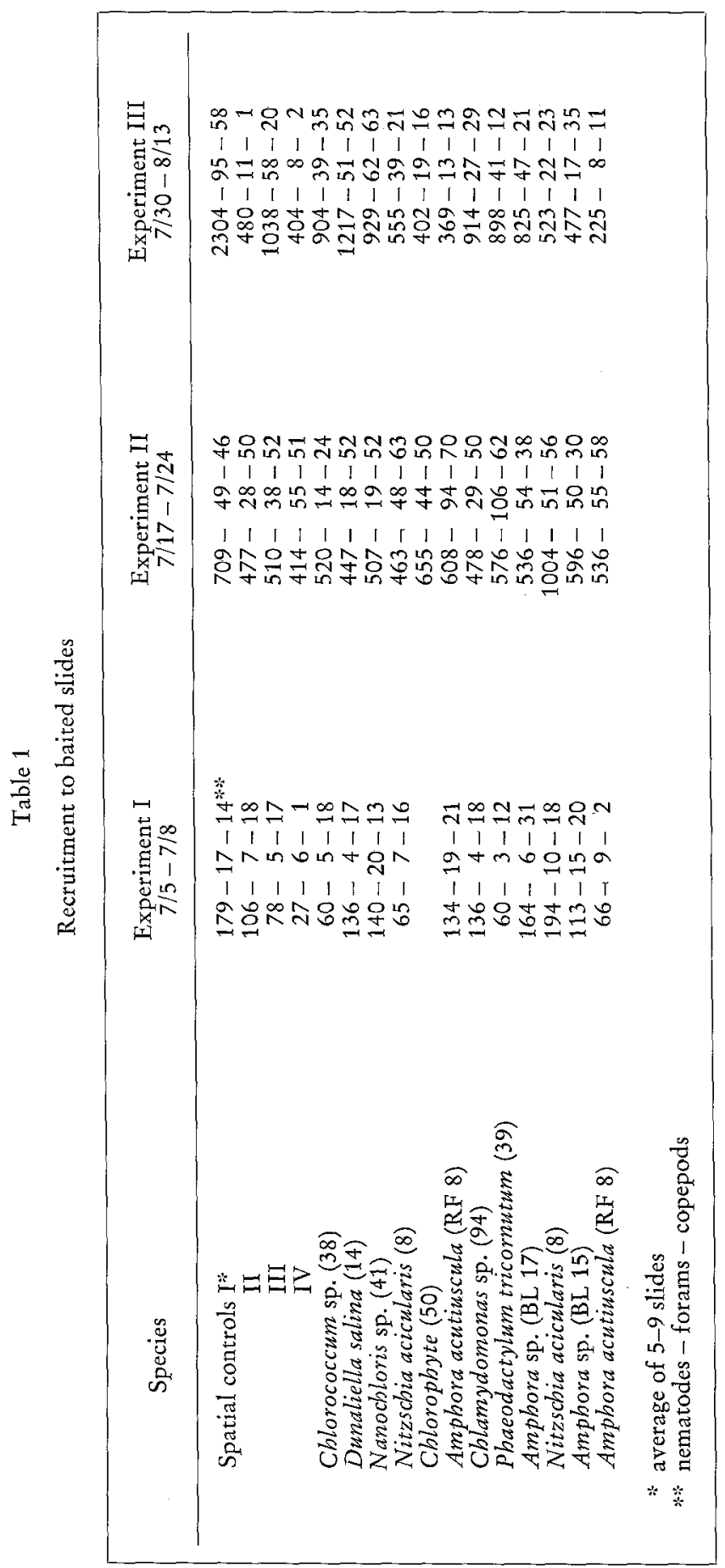


Those experiments involving field work were done in 2 successive summers while in residence at the Marine Biological Laboratory, Woods Hole, Mass., USA.

Some additional laboratory experiments were performed with the foraminifer Allogromia laticollaris and 2 species of algae, Nitzscbia acicularis and Dunaliella parva. Plates were either uniformly inoculated with either organism, divided into uniformly inoculated algal alternating quadrants, or 4 or 8 algal patches of one species in a uniform background of the other species. Uninoculated discs of media were used as controls.

Analysis of variance was performed with the aid of the UCLA Health Sciences Computer Program BMDOLV.

\section{RESULTS AND DISCUSSION}

Both experimental approaches clearly demonstrated that selective recruitment of meiofauna by particular algal patches is a mechanism which can establish spatial heterogeneity in meiofaunal populations. Our conclusion is based on the distribution of nematodes, foraminifera and copepods which are the most frequently encountered meiofauna in our field locations. Ostracods, large ciliates, gastrotrichs, rotifers, nauplii and other invertebrate larvae occur in too few numbers to yield statistically significant information on these organisms. In the baited slide experiments we enumerated the organisms from a total of 144 control and experimental slides in 3 separate experiments. Great variance was found in the absolute numbers of animals recovered from both control slides and experimental slides coated with the same algal species both incubated in different quadrants of the experimental meter in the same experiment or in successive experiments (Table 1). We judge this to be due to differences in populations of organisms available for recruitment at the fairly well separated $(\sim 0.7 \mathrm{~m})$ experimental sites. We, therefore, based our analysis of variance on differences between replicate baited slides and control slides in the same experimental set. The number of meiofauna recovered per slide increased with incubation time. For example we recovered a mean of 110.5 ( \pm 49.6), 564.7 ( \pm 140.7) and 780.8 ( \pm 495.2) nematodes per slide for slides incubated 3,7 and 14 days respectively. Corresponding values for forams were 9.1 ( \pm 4.77$), 50.4( \pm 35.1), 34.8$ ( \pm 24.0 ) and for copepods 15.7 ( \pm 7.2 ), $50.3( \pm 11.7)$ and $25.8( \pm 18.7)$ respectively for the same time periods. In many instances we noted juvenile forms on the slides, indicating possible meiofaunal reproduction in situ. The decline in numbers of forams and copepods recovered from the slides incubated for the longest time may indicate migration of juveniles away from their sites of production or depletion or changes in algal resources on the experimental slides. Because it is extremely time consuming we have not yet analyzed the algal populations on the slides to check this latter point, but we have prepared replicate microscope slides for future analysis. Analysis of variance between replicate slides coated with the same algal species and control slides from the same experimental subsets yielded $\mathrm{F}$ ratios of $19.762,10.653$ and 27.062 for nematodes, forams and copepods respectively indicating significant differences between them $\left(\mathrm{F}_{.99} \approx 5.03\right)$. We noted that in various subsets slides baited with particular algal species had recruited 
in the same experiments ( $\mathrm{F}$ ratio 2.02, $\mathrm{F} .99$ 5.3). There were very significant differences between the animal populations on experimental algal patches and control areas (nematodes $\mathrm{F}_{.99}=2.64$; forams $\mathrm{F}_{.98}=2.01$; copepods $\mathrm{F}_{.95}=1.97$; nauplii $\mathrm{F}_{.95}=2.12$; large ciliates $F_{.95}=2.16$; other groups insufficient data). As in the baited slide experiments, there were significant differences in the fauna recruited by patches of various species of algae (overall $F$ ratio 25.3; significant at the $5 \%$ level) but the attractiveness of a particular algal species varied in successive experiments presumably as a function of the specific animals available in the community for recruitment at the time of each experiment (Table 2). We observed microscopically that there were often changes in the animal populations of patches over a period of several days (Table 2). In some cases populations gradually built up by recruitment and then declined. In other cases reproduction was noted temporarily building up the populations and was followed by dispersal of the offspring.

The "cafeteria" experiments with gnotobiotic laboratory cultures were quite reproducible and in general they gave results consistent with previous tracer feeding and gnotobiotic grown experiments (Lee et al., 1966, 1969; Tietjen et a1., 1970; Tietjen \& Lee, 1973, 1977). Since the experiments were relatively short (less than the generation times of the meiofauna tested) recruitment to algal patches was the main source of the heterogeneous distribution of the animals. The 4 algal eating species of meiofauna each favored particular algal patches over others (Table 3). Leptocaris brevicornis was the most selective of the meiofauna tested; $80 \%$ of the inoculum was found in patches of Nanochloris sp. while few were found in patches of Chlamydomonas subcordiformis, Phaeodactylum tricornutum, Cylindrotheca closterium or Dunaliella parva. Chlamydomonas subcordiformis, on the other hand, attracted more Allogromia laticollaris than did the other species of algae tested. When the algal patches were expanded, or when the plates were sectored, A. laticollaris showed even stronger tendencies for attraction to particular patches and heterogeneous distribution. Chromadorina germanica was most strongly attracted to Phaeodactylum tricornutum and Cylindrotbeca closterium. The distribution of Rhabditis marina, a bactivorous species, was very interesting. It seemed to strongly avoid patches of 3 species of algae, Cylindrotheca closterium, Dunaliella parva and Nanochloris sp., but otherwise is was randomly distributed on both control and experimental patches.

Because of the economic and medical importance of nematodes, their behavioral responses to various types of stimuli have received significant attention (recently reviewed by Croll, 1970; Nicholas, 1976). There is considerable evidence that plant parasitic nematodes are attracted to the roots of particular species of plants. In an experiment similar to our first approach, but without controls, Meyers \& Hopper (1967) found that mats of 2 species of marine fungi, Dendryphiella arenaria and Halosphaeria mediostigera staked out on sand flats for several days attracted large numbers of Metoncholaimus sp. and lesser numbers of Monbystera, Prochromadorella, Araeolaimus, Acanthonchus, Diplolaimella, Chromadora, Symplocostoma and Viscosia. Recently students of behavioral genetics have been attracted to study chemotaxis and the sensor anatomy of Caenorbabditis elegans (Dusenberry, 1973, 1975, 1976; Ward et al., 1975; Ware et al., 1975). C. elegans, a not too distant relative of $R$ habditis marina, avoids $\mathrm{D}$-trypthophan with a threshold in the range of $10^{-3}-10^{-4} \mathrm{M}$ but 
Food quality and spatial distribution of meiofauna

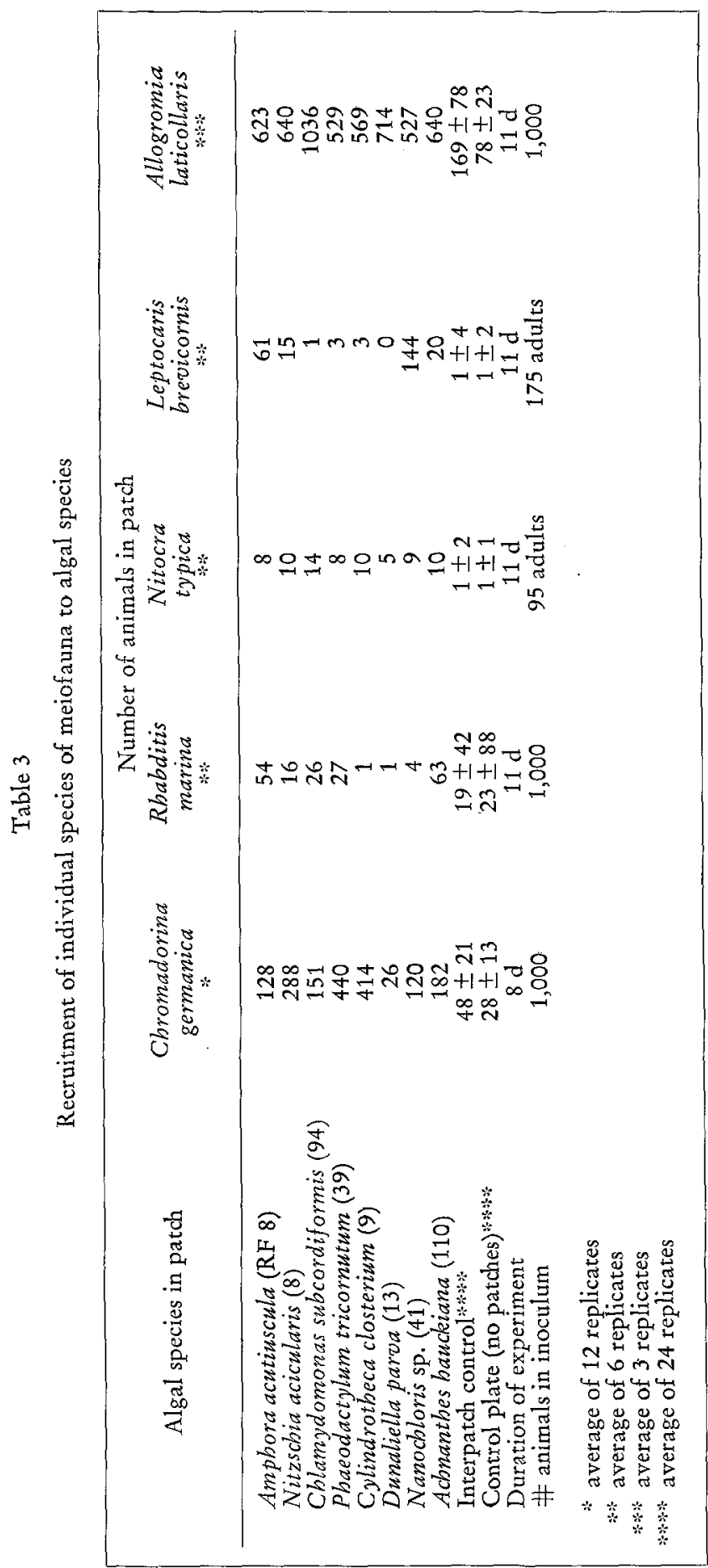


was insensitive to concentrations up to $10^{-2} \mathrm{M}$ of L-tryptophan. Though Dusenbery (1976) wondered about the adaptive value of this response to the organism in its natural environment there are some possible explanations. Since many bacteria incorporate D-amino acids into their cell walls and capsules we suggest that $C$. elegans may have an adaptation to avoid microhabitats especially heavily colonized by particular species of bacteria containing or releasing large quantities of $\mathrm{D}$-tryptophan. This type of problem might be more easily studied using Rhabditis marina since we have already identified patches of 3 species of algae which the worm avoids. Release of various metabolites including amino acids and carbohydrates by the algae is quite well known and much of the methodology required is now quite routine (Hellebust, 1974).

While we feel we have obtained strong evidence to suggest that algal colonies or blooms can selectively attract meiofauna and can be a factor causing the non-random distribution of these animals, with obvious cost-benefit advantages for the growth and reproduction of these animals, we cannot yet assess the importance of this phenomenon relative to other community organizing factors. We have found, for instance that many species of littoral foraminifera are more fecund on mixed diets of particular species of algae than on monalgal ones (Muller \& Lee, 1969). Evidence indicates that this may be the case for at least some copepod species as well. Forams can have feeding nets up to several $\mathrm{cm}$ which could be feeding in several algal patches at the same time.

Many species of littoral benthic foraminifera are algal patch makers themselves. They gather and transport captured algae from the edges of their feeding webs to their tests and often build huge balls or clumps of algae around themselves. Only a small fraction of the algae is used immediately as food. A part of the algal mass is used from time to time by the forams as surface on which to construct new test chambers or reproductive chambers (Grell, 1973).

Compared to other physical environments (i.e. rocky shore) the salt marsh littoral is relatively benign. In common with many benign environments (i.e. forest floors) the biota of the littoral is seasonal, relatively transient, but predictable. Many selective forces are operating in time and space as the assemblages in the littoral go through their annual successional trajectories. Because so many questions remain, there is not yet sufficient evidence to build a conceptual framework which would clarify the tradeoffs of the various selective factors which shape the biotic assemblages of the lower and intermediate steps in the salt marsh detrital food webs. Those meiofauna and microfauna which have been carefully studied seem to segregate by partitioning the available microflora (Fenchel, 1968; Lee et al., 1966, 1975; Muller, 1975). How often do they encounter blooms of "ideal" food organisms in nature? How do consumption rates and efficiencies vary with abundance and time? What are the relative replacement or turnover rates of these small plants and animals in time and in space? What role does competition among the various organisms play in the 4-dimensional spacing of the organisms in the community successional trajectory? What role do the macrofauna play in structuring the assemblages of smaller organisms? Do the macrofauna selectively harvest the smaller animals? Are the initial colonizations of Spartina, Zostera, and macrophytes selective or stochastic? How readily acceptable are new recruits to these communities? While the major abiotic and biotic factors which help to establish and maintain relatively permanent communities (i.e. rocky shores and 
northern temperate forests) seem to be known, we must for the moment, content ourselves by asking and answering many more questions.

Acknowledgements. This work was supported by National Science Foundation Grant. The authors wish to acknowledge the technical assistance of Monica J. Lee in some of the field and laboratory work.

\section{LITERATURE CITED}

Buzas, M. A., 1965. The distribution and abundance of foraminifera in Long Island Sound. Smithson. misc. Collns 149, 1-89.

- 1969. Foraminiferal species densities and environmental variables in an estuary. Limnol. Oceanogr. 14, 411-422.

Connell, J. H., 1975. Some mechanisms producing structure in natural communities. In: Ecology and evolution of communities. Ed. by M. L. Cody \& J. M. Diamond. Belknap Press, Cambridge, 460-490.

Croll, N. A., 1970. The behaviour of nematodes. Arnold, London, $118 \mathrm{pp.}$

Dusenbery, D. B., 1973. Countercurrent separation: a new method for studying behavior in small aquatic organisms. Proc. natn Acad. Sci. U.S.A. 70, 1349-1352.

- 1974. Analysis of chemotaxis in the nematode Caenorbabditis elegans by countercurrent separation. J. exp. Zool. 188, 41-48.

- 1975. The avoidance of D-tryptophan by the nematode Caenorbabditis elegans. J. exp. Zool. 193, 413-418.

Fenchel, T., 1968. The ecology of marine microbenthos. II. The food of marine benthic ciliates. Ophelia 5, 73-121.

Grell, K., 1973. Protozoology. Springer, Berlin, 552 pp.

Hellebust, J. A., 1974. Extracellular products. In: Algal physiology and biochemistry. Ed. by W. D. P. Stewart. Univ. of California Press, Berkeley, 838-863.

Hutchinson, G. E. \& MacArthur, R. H., 1959. A theoretical ecological model of size distributions among species of animals. Am. Nat. 93, 117-125.

Lee, J. J., 1974. Toward understanding the niche of foraminifera. In: Foraminifera. Ed. by R. H. Hedley \& G. Adams. Acad. Press, New York, 1, 201-260.

- \& Muller, W. A., 1973. Trophic dynamics and niches of salt marsh foraminifera. Am. Zool. $13,215-225$.

- Tietjen, J. H. \& Garrison, J., 1976. Seasonal switching in the nutritional requirements of Nitocra typica Boeck, a harpacticoid copepod from salt marsh aufwuchs communities. Trans. Amer. microsc. Soc. 95, 628-637.

- Tenore, K. R., Tietjen, J. H. \& Mastropaolo, C., 1976. An experimental approach toward understanding the role of meiofauna in a detritus based marine food web. Spec. Publ. Ecol. Soc. Amer. 1, 140-147.

- McEnery, M., Pierce, S., Freudentha1, H. \& Muller, W. A., 1966. Tracer feeding experiments in feeding littoral foraminifera. J. Protozool. 13, 659-670.

- Muller, W. A., Stone, R. J., McEnery, M. E. \& Zucker, W., 1969. Standing crop of foraminifera in sublittoral epiphytic communities of a Long Island salt marsh. Mar. Biol. 4, 44-61.

- Tietjen, J. H., Stone, R. J., Muller, W. A., Rullman, J. \& McEnery, J. 1970. The cultivation and physiological ecology of members of salt marsh epiphytic communities. Helgoländer wiss. Meeresunters. 20, 136-156.

Matera, N. J. \& Lee, J. J., 1972. Environmental factors affecting the standing crop of foraminifera in sublittoral and psammolittoral communities of a Long Island salt marsh. Mar. Biol. 14, 89-103.

Meyers, S. P. \& Hopper, B., 1967. Studies on marine fungal-nematode associates and plant degration. Helgoländer wiss. Meeresunters. 15, 270-281. 
Muller, W. A., 1975. Competition for food and other niche-related studies of 3 species of salt marsh foraminifera. Mar. Biol. 31, 339-351.

- \& Lee, J. J., 1969. Apparent indispensability of bacteria in foraminiferan nutrition. J. Protozool. 16, 471-478.

Nicholas, W. L., 1976. The biology of free living nematodes. Oxford Univ. Press, London, 219 pp.

Pielou, E. C., 1975. Ecological diversity. Wiley, New York, 165 pp.

Provasoli, L., Shiraishi, K. \& Lance, J. R., 1959. Nutritional idiosyncrasies of Artemia and Tigriopus in monoxenic culture. Ann. N.Y. Acad. Sci. 77, 250-261.

Rubin, H. A. \& Lee, J. J., 1976. Informational energy flow as an aspect of the ecological efficiency of marine ciliates. J. theor. Biol. 62, 69-91.

Schoener, T. W., 1974. Resource partitioning in ecological communities. Science, N.Y. 185, $27-39$.

Steele, J. H. (Ed.), 1973. Theoretical problems. Part VI: Introduction, Recycling of organic matter. Oliver \& Boyd, Edinburgh, 415-418.

Tietjen, J. H. \& Lee, J. J., 1973. Life history and feeding habits of the marine nematode Chromadora macrolaimoides Steiner. Oecolgia 12, 303-314.

- - 1977. Feeding behaviour of marine nematodes. In: Ecology of marine benthos. Ed. by B. C. Coull. Univ. South Carolina Press, Columbia. 22-36.

- - Rullman, J., Greengart, A. \& Trompeter, J., 1970. Gnotobiotic culture and physiological ecology of the marine nematode Rhabditis marina Bastian. Limnol. Oceanogr. 15, $535-543$.

Ward, S., Thomson, N., White, H. G. \& Brenner, S., 1975. Electron microscopical reconstruction of the anterior sensory anatomy of the nematode Caenorbabditis elegans. J. comp. Neurol. 160, 313-338.

Ware, R. W., Clark, D., Crossland, K. \& Russell, R. L., 1975. The nerve ring of the nematode Caenorbabditis elegans: sensory input and motor output. J. comp. Neurol. (In press).

First author's address: Prof. J. J. Lee

Department of Biology

The City College

Convent Avenue at 138th Street

New York, New York 10031

USA 